\title{
Multi-material design in additive manufacturing-feasibility validation
}

\author{
M. Leicher ${ }^{1} \cdot$ S. Kamper ${ }^{1} \cdot$ K. Treutler $^{1} \cdot$ V. Wesling ${ }^{1}$ \\ Received: 21 October 2019 / Accepted: 8 March 2020 / Published online: 8 May 2020 \\ (C) The Author(s) 2020
}

\begin{abstract}
The present investigations on generative manufacturing using metallic materials pursue the idea of transferring the microscopic structural morphology of a dual-phase steel in modified form to the macroscopic level. The aim is to be able to join materials of different lattice modifications and to combine their positive properties. This applies in particular to the combination of high tensile strength and good formability. For this investigation, a specimen was created from a high-strength ferritic/martensitic (25\%) and an austenitic (75\%) material with a defined welding sequence. The specimen was deliberately manufactured anisotropically using welding layers in order to quantify its properties. Tensile tests were performed on specimens with different weld seam orientations to determine the direction-dependent properties. As can be proven by the results, the application of welding processes with different materials results in an anisotropic behaviour in generative manufacturing. With regard to tensile strength and elongation, there is an integral value of the mechanical-technological properties of both base materials. The existing anisotropy can be utilized with regard to the design by adapting the alignment of the weld layers to the load.
\end{abstract}

Keywords WAAM $\cdot$ Multi-material design $\cdot$ Additive manufacturing

\section{Introduction}

The increasing importance of resource-efficient handling of raw materials is driving development to design components more efficiently. As a result, manufacturing processes are being reorganized and the trend is that components are no longer milled from the "solid", but generated using 3D printing

Recommended for publication by Commission I - Additive Manufacturing, Surfacing, and Thermal Cutting

This article is part of the collection Additive Manufacturing - Processes, Simulation and Inspection

M. Leicher

leicher@isaf.tu-clausthal.de

S. Kamper

office@isaf.tu-clausthal.de

K. Treutler

office@isaf.tu-clausthal.de

V. Wesling

office@isaf.tu-clausthal.de

1 Institut of Welding and Machining, TU Clausthal, Agricolastraße 2, Clausthal-Zellerfeld, Germany processes. Generative manufacturing processes, such as wire arc additive manufacturing (WAAM), can increase the degree of material utilization [1-4]. The CMT arc welding technology is feasible for manufacturing bead structures [5-7]. Furthermore, this process offers the possibility of a multimaterial design. For this purpose, different materials are specifically combined with each other in order to adjust local mechanical properties to the strains. For the targeted adjustment of the mechanical properties, the basic idea is to transfer the microscopic structure of the dual-phase steel or duplex steel in modified form to the macroscopic level [7]. The combination of morphologies is intended to utilize advantages of the microstructures, thereby increasing the effectiveness and variety of possible part designs. In addition, the arc-based generative manufacturing offers the possibility to locally adjust the material properties depending on the load, due to the process immanent conditions. This kind of multi-material design is exclusive to additive manufacturing processes.

Furthermore, an anisotropic behaviour can be achieved by using welding layers. The mechanical properties are specifically enhanced by the alignment of the layers. The result of this targeted integration of materials and layer alignment is an exact adjustment of the mechanical properties to the existing strains [8]. 
a)

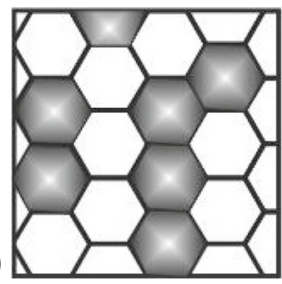

b)

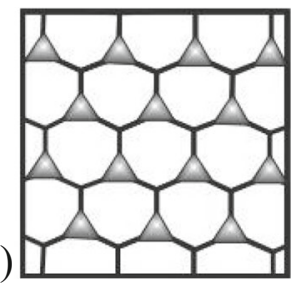

Fig. 1 Schematic structure. a Duplex steel. b Dual-phase steel [9]

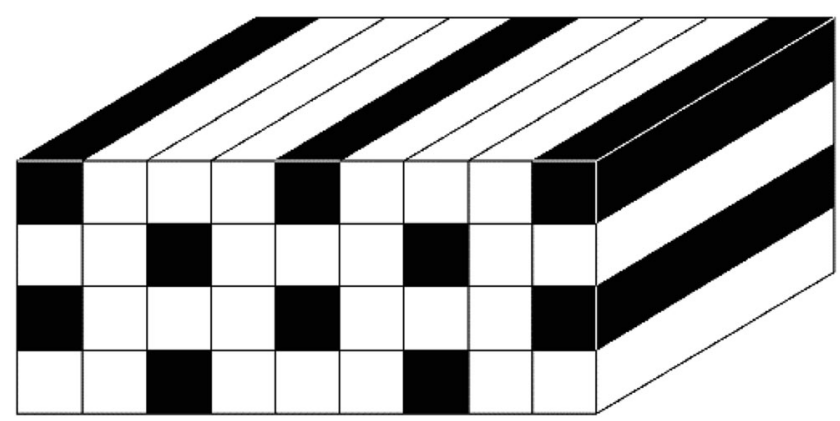

Fig. 2 Division of the layers (white: soft matrix, black: high-strength deposits)

Table 3 Process parameter

\begin{tabular}{lll}
\hline Filler metal & FeNi36 & Mn4Ni1,5CrMo \\
\hline Stickout (mm) & 15 & 15 \\
Wire diameter (mm) & 1.14 & 1.2 \\
Wire feed (m/min) & 4.5 & 5.0 \\
Welding velocity (m/min) & 0.3 & 0.3 \\
Gas & M21 & M21 \\
Current (I) & 152 & 165 \\
Voltage (V) & 14.7 & 15.2 \\
Process & CMT & CMT \\
\hline
\end{tabular}

The specimen will be welded by stringer bead welding. The soft matrix is represented by the austenitic FeNi36 with the standard designation EN Ni36 (Table 1). The high-strength part is a filler metal Mn4Ni1,5CrMo with the standard designation DIN EN ISO 16834-A G 69 [15] (Table 2).

Both the pure welding wires and the weld metal of the Mn4Ni1,5CrMo are classified in the Schaeffler diagram in

Figure $1 \mathrm{~b}$ shows the schematic representation of a dualphase steel, which are characterized by a low carbon content and consist of a ferritic matrix in which about $20 \%$ martensite is embedded [11].

These two microstructures result in a fusion of the positive properties of the individual parts. This principle can, in a figurative sense, be applied to the macroscopic level. Above all, the combination of the different advantages of the different materials should lead to an adaptation of the mechanical properties $[12,13]$.

A soft metal matrix reinforced with hard areas improves the mechanical-technological properties with regard to strength and toughness.

Table 2 Chemical composition Mn4Ni1,5CrMo [16]

Main alloying additions in filler wire (wt.\%)

\begin{tabular}{lllllll}
\hline $\mathrm{C}$ & $\mathrm{Si}$ & $\mathrm{Mn}$ & $\mathrm{Cr}$ & $\mathrm{Ni}$ & $\mathrm{Mo}$ & $\mathrm{Ti}$ \\
\hline 0.09 & 0.55 & 1.67 & 0.25 & 1.6 & 0.5 & 0.07 \\
\hline
\end{tabular}

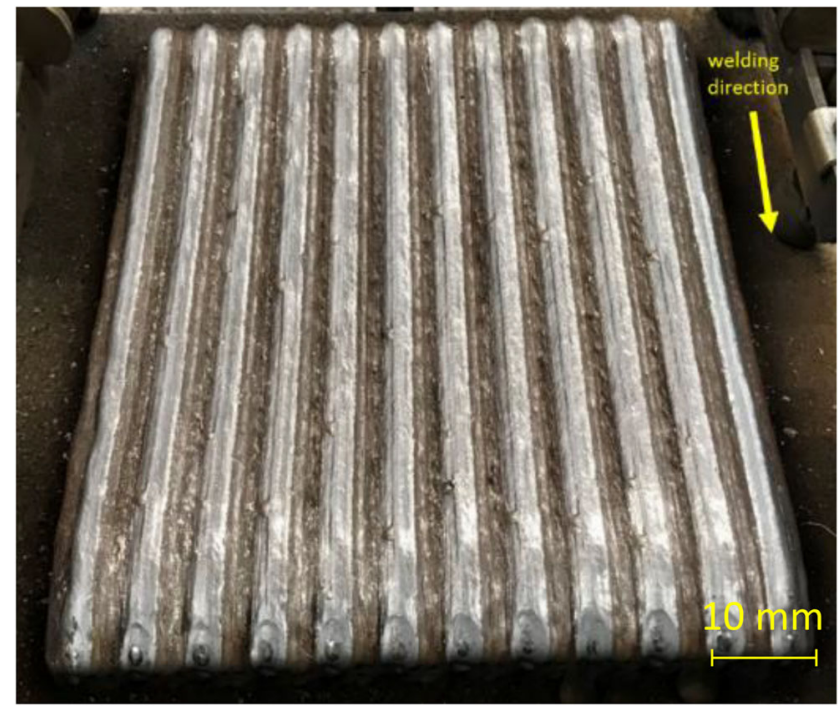

Fig. 3 Welded specimen 
a)

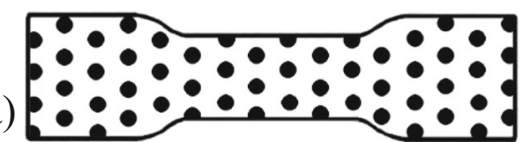

b)

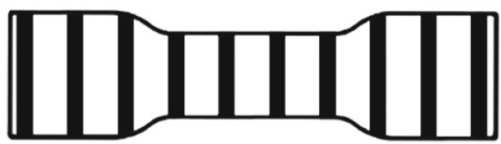

c)

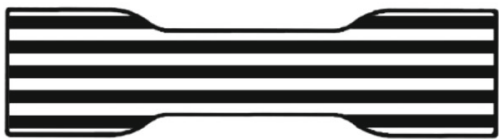

Fig. 4 Layer orientation of the tensile specimens (black represents Mn4Ni1,5CrMo). a Transverse upright. b Transverse flat. c Longitudinal upright

form of the nickel and chromium equivalent, with FeNi36 being outside the evaluable range.

Formula for calculating the nickel equivalent [17]:

$\mathrm{Ni}_{\mathrm{Equ}}=\% \mathrm{Ni}+30 \cdot \% \mathrm{C}+0.5 \cdot \% \mathrm{Mn}$

Formula for calculating the chrome equivalent [17]:

$\mathrm{Cr}_{\mathrm{Equ}}=\% \mathrm{Cr}+\% \mathrm{Mo}+1.5 \cdot \% \mathrm{Si}+0.5 \cdot \% \mathrm{Nb}+2 \cdot \% \mathrm{Ti}$

\section{Experimental investigation}

To produce the specimen, the layers of the FeNi36 were welded first. The Mn4Ni1,5CrMo welding beads were inserted into the gaps between the weld seams. This procedure creates a soft matrix with high-strength components. Due to the simple layer structure for welding, the soft matrix represents in this first investigation a percentage of $75 \%$ of the test specimen with an insular distribution of the high-strength steel. This can be seen schematically in Fig. 2 .

\subsection{Welding parameters}

Due to the different welding filler materials, different welding parameters are required to produce the specimen with alternating line beads. The parameters listed in Table 3 have shown a particularly good surface quality between the individual bead layers.

To produce the specimen, three stringer beads of FeNi36 were alternately welded to one stringer bead of Mn4Ni1,5CrMo. As seen in Fig. 2, the white parts are the FeNi36 and were welded first from left to right and let gaps on the black parts. These parts were filled after a change of the welding wire with stringer beads of Mn4Ni1,5CrMo. In this layer structure, test piece was built up a height of ten layers. The welded specimen is shown in Fig. 3.

\subsection{Sample preparation}

To investigate the mechanical-technological properties and a possible anisotropy of the multi-material design, tensile samples were taken. These were manufactured in different orientations to the weld layers and then subjected to destructive tensile tests.

The alignments are transverse upright to the welding direction, transverse flat to the welding direction and longitudinal upright to the welding direction. These are shown schematically in Fig. 4. The different alignments are used to investigate whether anisotropic behaviour occurs and whether multimaterial construction is feasible.
Fig. 5 Schaeffler diagram with classification of the Mn4Ni1,5CrMo position [17]

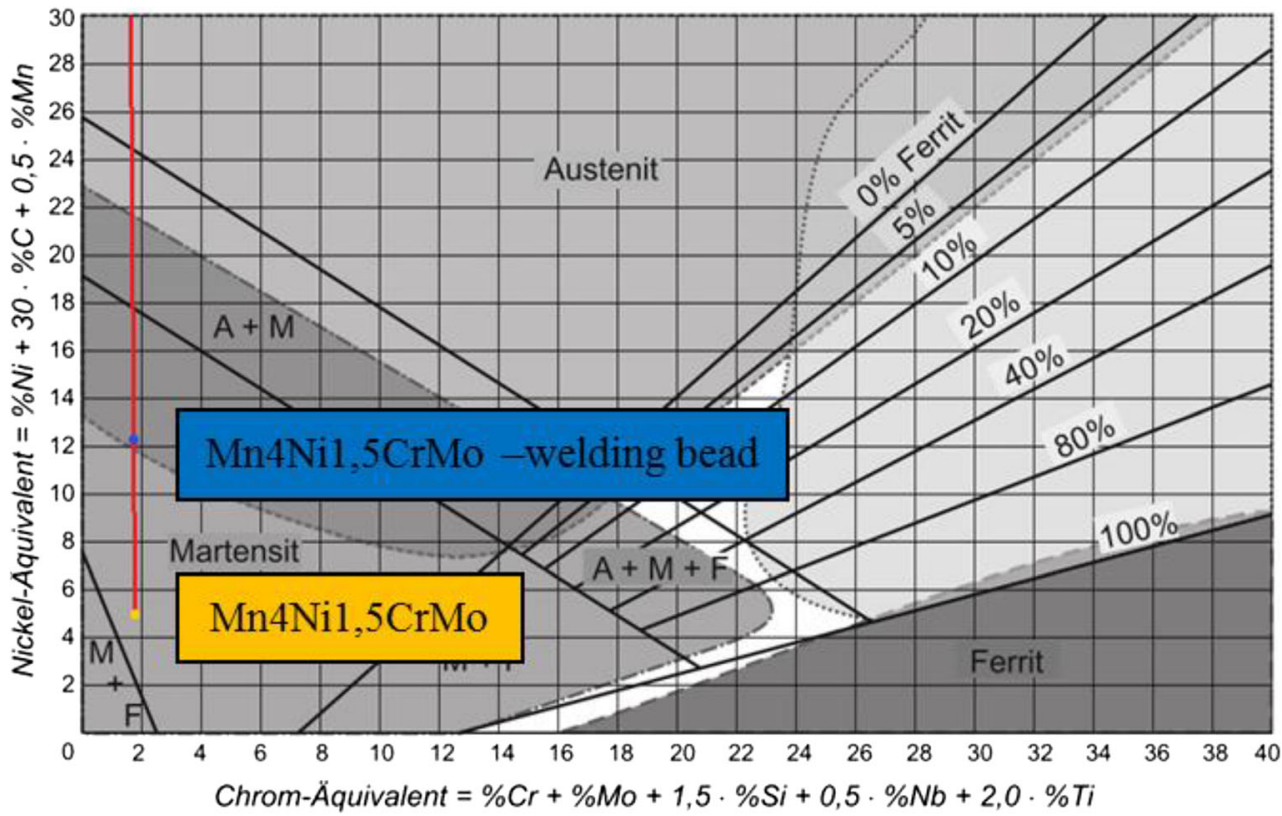


Fig. 6 Layer 1 (left) and layer 2 (right) of Mn4Ni1,5CrMo weld metal
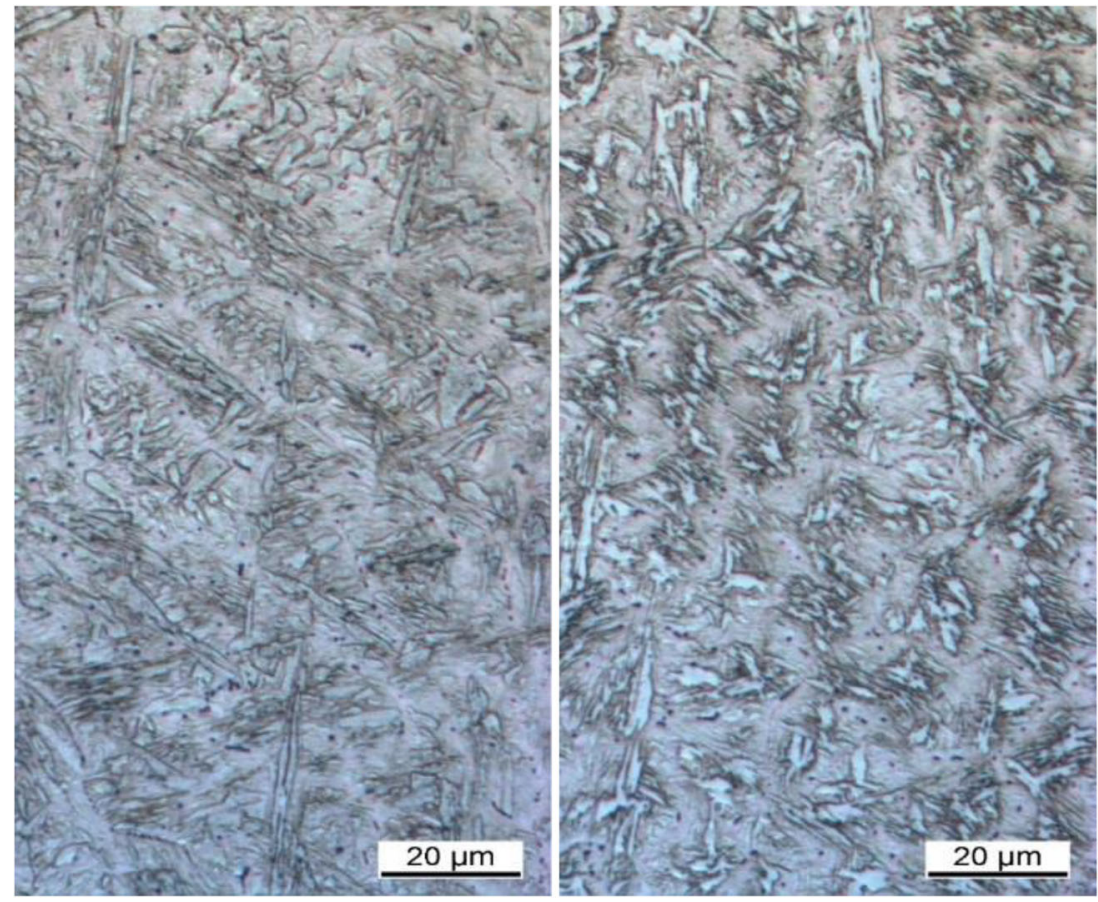

In addition, a microsection and a specimen for hardness measurement were created from the welded specimen. The transition areas between FeNi36 and Mn4Ni1,5CrMo were examined metallographically. The joining of the two materials and the absence of cracks, pores and inclusions were carefully examined. Furthermore, the microstructures are analysed.

\section{Results}

\subsection{Structural morphology}

The morphology of the microstructures is examined and their susceptibility to hot and cold cracking is classified with reference to the Schaeffler diagram. Only the weld metal of the
Fig. 7 Layer 3 (left) and layer 4 (right) of Mn4Ni1,5CrMo weld metal

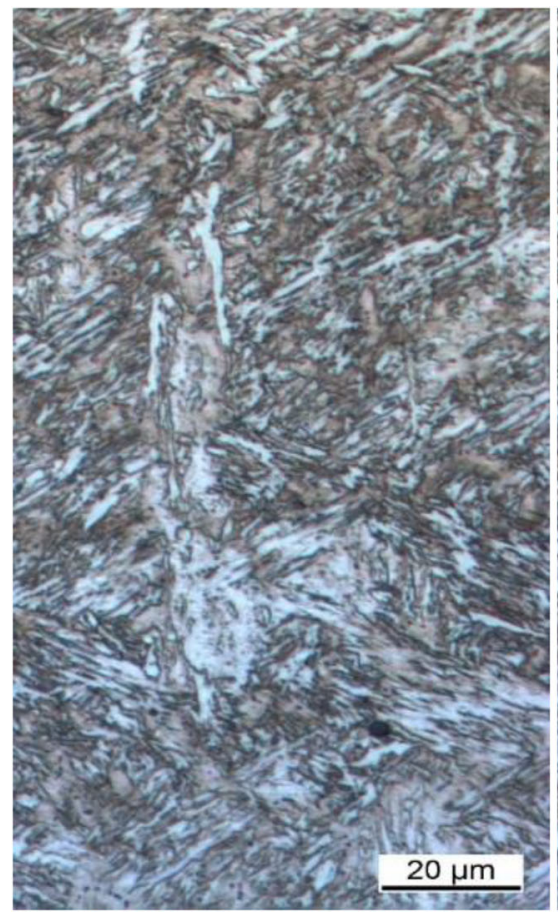




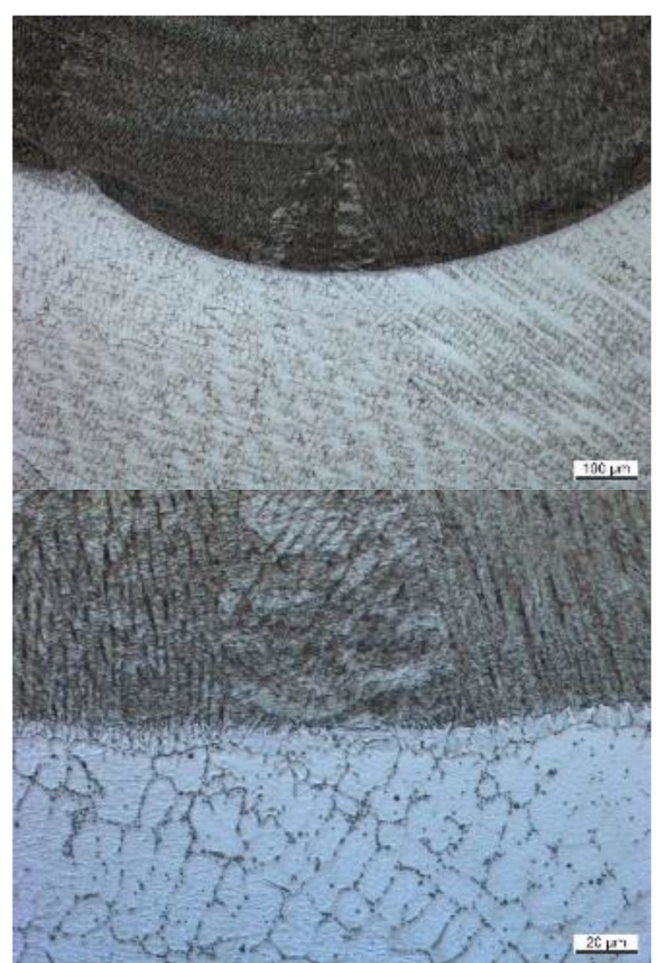

Fig. 8 Layer 3 (top) and layer 4 (down) of Mn4Ni1,5CrMo weld metal

Mn4Ni1,5CrMo is classified by the diagram, since the FeNi36 is outside the nickel equivalent and therefore cannot be determined. The weld metal of the Mn4Ni1,5CrMo is calculated with a process-related mixing of $20 \%$. According to formula (1), this results in a nickel equivalent $\mathrm{Ni}_{\mathrm{Equ}}$, weld metal, $\mathrm{Mn} 4 \mathrm{Ni1}, 5 \mathrm{CrMo}=12.331 \%$, and according to formula (2), a chromium equivalent of $\mathrm{Cr}_{\mathrm{Equ}, \text { weld metal, } \mathrm{Mn} 4 \mathrm{Ni1}, 5 \mathrm{CrMo}}=$ $1.676 \%$. In comparison, the pure filler metal equals to $\mathrm{Ni}_{\ddot{A ̈ q u}, \mathrm{Mn} 4 \mathrm{Ni} 1,5 \mathrm{CrMo}}=5.135 \%$ and $\mathrm{Cr}_{\mathrm{Äqu}, \mathrm{Mn} 4 \mathrm{Ni} 1,5 \mathrm{CrMo}}=$ $1.715 \%$. If these values are classified in the Schaeffler diagram, the points shown in Fig. 5 result. The pure filler metal $\mathrm{Mn} 4 \mathrm{Ni1}$,5CrMo is in the purely martensitic range and is susceptible to cold cracking. Through the combination with FeNi36, the Mn4Ni1,5CrMo weld metal is shifted in the direction of the martensitic-austenitic range. This shift increases the susceptibility to hot cracking because of $20 \%$ mixing with FeNi36, while the susceptibility to cold cracking below $400{ }^{\circ} \mathrm{C}$ remains unchanged.

Figure 6 shows that layer 1 has a martensitic structure. The needle-like structure of the martensitic is homogeneously distributed over the entire section. Compared with the other layers, it is finer-grained, since no further welding process takes place over these layers and thus no additional heat influence on the microstructure occurs. The black spots in the microstructure are the smallest carbides formed from the melt.

Layer 2 also has a martensitic structure with austenitic and ferritic islands, depends on the mixing in the stinger bead. Since this was reheated due to the layer welded above it, part of the carbon, dissolved in the body-centred tetragonal martensite
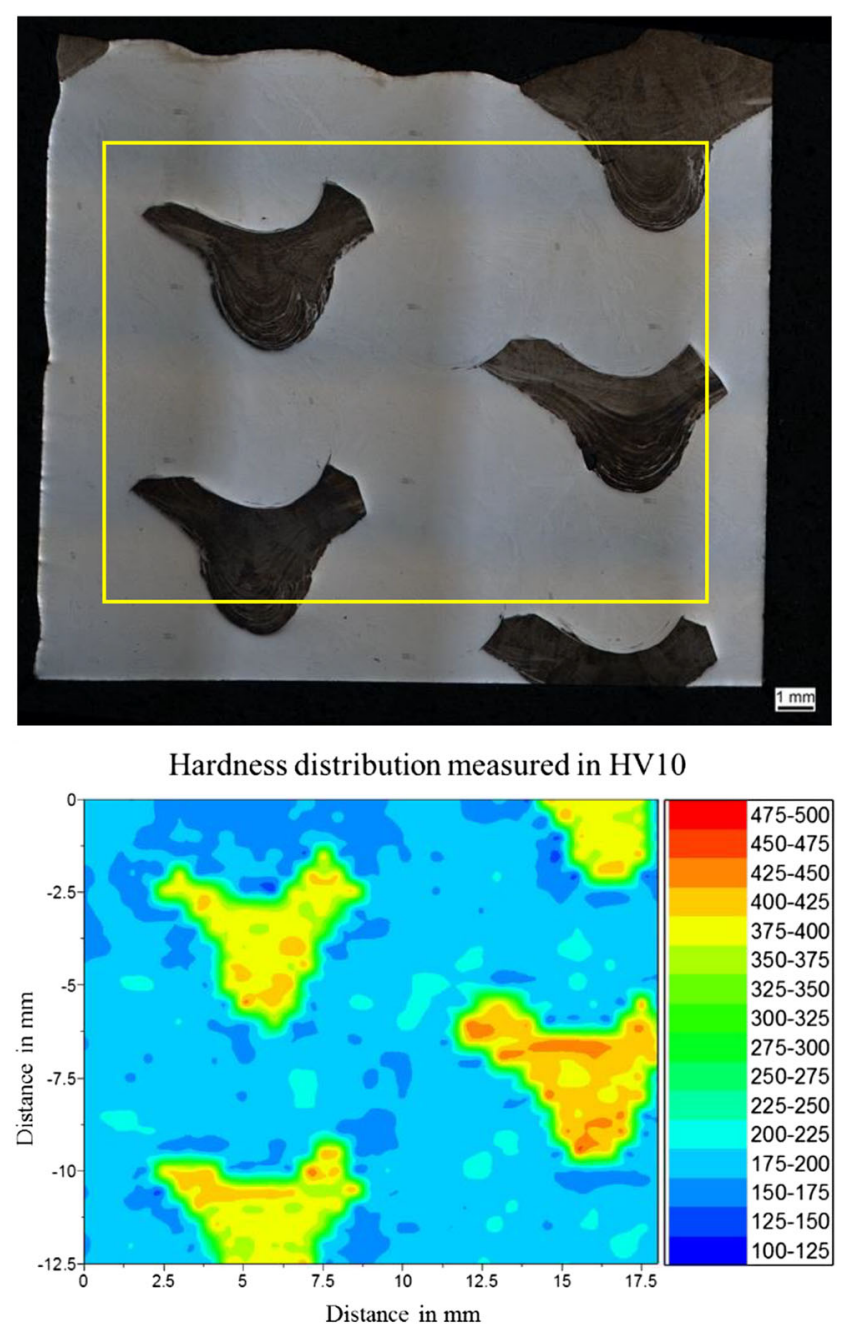

Fig. 9 Hardness distribution

lattice, could diffuse and thus fold down into austenite and a body-centred cubic ferritic lattice.

Figure 7 shows that layer 3 has larger areas of ferrite and austenite than layer 1 or 2 . This is due to the heat input by the welding process. It is noticeable that the ferrite is acicular, as it has no time to grow due to the cooling speed. This also applies to layer 4. In contrast to layer 3, this microstructure is finer and more homogeneous. Due to the influence of temperature, cementite is precipitated at the ferrite grain boundaries by diffusion processes. In addition, no carbides are visible in the lower layers.

The microstructure of the cross section was examined to determine the microstructure morphologies of the individual phases. The high-strength weld seams made of Mn4Ni1,5CrMo have an

Table 4 Mechanical properties of base material according to data sheet $[14,16]$

\begin{tabular}{llll}
\hline Material & $\mathrm{R}_{\mathrm{p} 0.2}\left(\mathrm{~N} / \mathrm{mm}^{2}\right)$ & $\mathrm{R}_{\mathrm{m}}\left(\mathrm{N} / \mathrm{mm}^{2}\right)$ & $\mathrm{A}(\%)$ \\
\hline FeNi36 & 310 & 490 & 30 \\
Mn4Ni1,5CrMo & 720 & 790 & 17 \\
\hline
\end{tabular}


Table 5 Mechanical properties welding specimen (average of 5 samples each)

\begin{tabular}{llll}
\hline Sample & $\mathrm{R}_{\mathrm{p} 0.2}\left(\mathrm{~N} / \mathrm{mm}^{2}\right)$ & $\mathrm{R}_{\mathrm{m}}\left(\mathrm{N} / \mathrm{mm}^{2}\right)$ & $\mathrm{A}(\%)$ \\
\hline Transverse upright & 439.27 & 591.20 & 8.28 \\
Transverse flat & 432.73 & 568.60 & 7.34 \\
Longitudinal upright & 459.44 & 656.83 & 14.93 \\
\hline
\end{tabular}

austenitic-ferritic/martensitic structure. The soft matrix of FeNi36, on the other hand, consists entirely of austenite.

Figure 8 shows the transition of the high-strength beads to the soft matrix. This shows two microstructures, which are separate from each other, as it corresponds to the idea. Furthermore, neither pores, cracks nor inclusions are visible. This shows that ferritic/martensitic and austenitic microstructures can exist side by side without a clear transition zone. The mixing between the two layers is marginal due to the low heat input. In order to avoid undesired effects such as brittle phase formation in the mixing zone, the two types of microstructure must be clearly separated from each other.

\subsection{Material characteristics}

The hardness distribution diagram in Fig. 9 shows the homogeneously distributed hardness of the FeNi36.The highstrength inclusions are clearly visible in the hardness measurement. This macrostructure resembles the microscopic appearance of a dual-phase steel and represents the basic idea of hard phases in a soft matrix.

To evaluate the mechanical properties, the tensile strength of the welded test piece is determined. A possible anisotropy can be detected by comparing the yield strength and ductility.

The mechanical properties of the base materials are listed in Table 4 for comparison.
Based on the mechanical properties of the base materials, the objective is to achieve an improvement in yield strength and tensile strength compared with FeNi36 and to approximate the yield strength and tensile strength of Mn4Ni1,5CrMo, while increasing ductility. However, welding defects cannot be excluded. These reduce the elongation at break under certain circumstances. The reason for this may be the selected layer structure, which will be modified and optimized in further investigations.

The mechanical properties of the welding specimens in Table 5 show that the yield strength as well as the tensile strength of the specimens is higher compared with FeNi36. The alignment with the respective tensile strengths and yield strengths is illustrated in Fig. 10. A supporting effect is achieved in the soft matrix with the high-strength incorporation. If the yield strengths are calculated according to the mixing rule using the phase fractions of $\mathrm{FeNi} 36$ and Mn4Ni1,5CrMo from base metal values, this is calculated as $\mathrm{R}_{\mathrm{p} 0.2}=412 \mathrm{~N} / \mathrm{mm}^{2}$. This value is below the experimentally determined values of the multi-material design. The phase fraction of the Mn4Ni1,5CrMo is higher, especially in the case of the sample with its longitudinal edge, due to the alignment. This is where the yield strength reaches the maximum value. The calculated determination of the tensile strength also results in a lower value than the experimental determination. The tensile strength calculated according to the mixing rule is $\mathrm{R}_{\mathrm{m}}=565 \mathrm{~N} / \mathrm{mm}^{2}$ from base metal values. The behaviour of the tensile strength is analogous to that of the yield strength and withstands the highest loads when stress is parallel to the welding direction.

If the tensile strength and ductility values are compared on the basis of the different layer orientation, it can be seen that an anisotropic behaviour in the workpiece can be achieved by using GMAW layers. In fact of welding defects, the ductility of the test specimen shows a loss.

The tensile strength and ductility show the anisotropic properties of the specimen based on the welding direction.
Fig. 10 Orientation of the tensile specimens taken

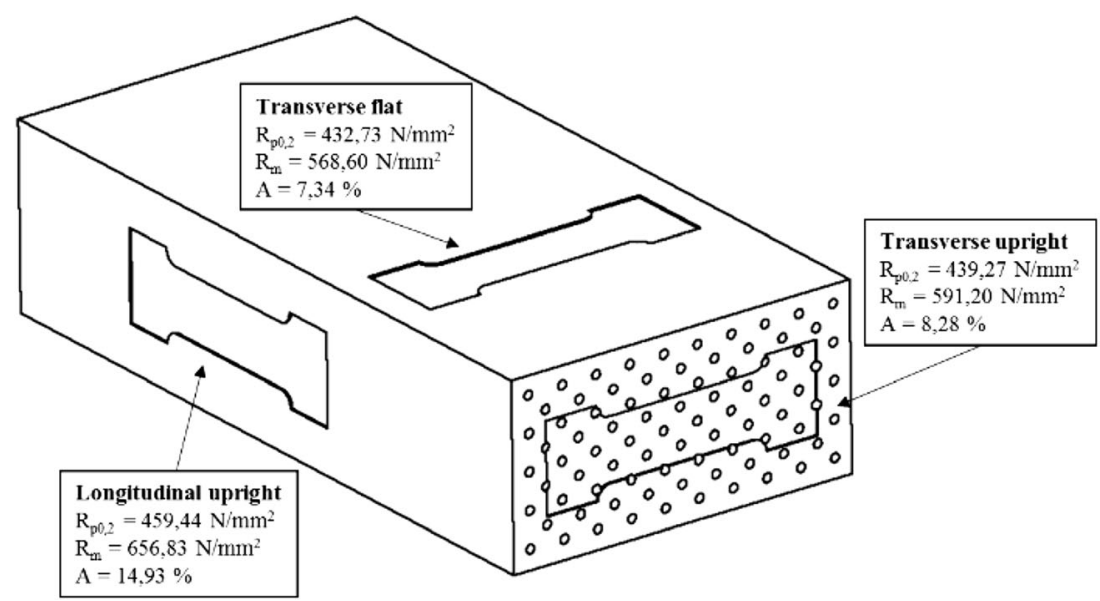


This can therefore be used in the wire arc additive manufacturing of load-adjusted workpieces.

\section{Conclusion}

The presented investigations show that a multi-material component design is achievable in arc-based generative manufacturing. Furthermore, it was shown that through the multi-material design, the material properties can be adapted locally to the load, since the two materials can be processed with each other without a clear transition zone. The tensile tests have shown that the soft matrix is supported by the high-strength inclusions and thus has a higher yield strength and tensile strength. Welding defects of the test specimen effect in a loss of ductility. In addition, a greater increase in yield strength and tensile strength can be achieved through the use of the multimaterial design than would be expected through the mathematical determination. After comparing the mechanical properties for the different orientations, an anisotropy of the material can be determined by using GMAW processes. This is of great advantage with regard to resource-efficient, load-oriented design adapted to local properties.

\section{Outlook}

The main focus is on investigating the ductility of the samples. This should be improved by a different layer arrangement. As further investigations, the influences on the fatigue strength are to be examined more closely. The aim is to examine the crack growth in a targeted manner. Furthermore, follow-up tests with different metal combinations will follow.

Acknowledgements The authors thank the company Fliess for providing the welding filler metals.

Funding Information Open Access funding provided by Projekt DEAL.

Open Access This article is licensed under a Creative Commons Attribution 4.0 International License, which permits use, sharing, adaptation, distribution and reproduction in any medium or format, as long as you give appropriate credit to the original author(s) and the source, provide a link to the Creative Commons licence, and indicate if changes were made. The images or other third party material in this article are included in the article's Creative Commons licence, unless indicated otherwise in a credit line to the material. If material is not included in the article's Creative Commons licence and your intended use is not permitted by statutory regulation or exceeds the permitted use, you will need to obtain permission directly from the copyright holder. To view a copy of this licence, visit http://creativecommons.org/licenses/by/4.0/.

\section{References}

1. Ding J, Martina F, Lockett H, Williams S et al (2015) Manufacture of complex titanium parts using wire+arc additive manufacture adrian addison. Titanium Europe

2. Artaza T, Alberdi A, Murua M et al (2017) Design and integration of WAAM technology and in situ monitoring system in a gantry machine. Manufacturing Engineering Society International Conference 2017

3. Bekker ACM, Verlinden JC , Galimberti G (2016) Callenges in assessing the sustainability of wire + arc additive. In: Solid Freeform Fabrication, Austin TX

4. Chabot A, Rauch M, Hascoët J-Y (2019) Towards a multi-sensor monitoring methodology for AM metallic processes. Welding in the World 63:759-769

5. Rodriguez N, Vázquez L, Huarte I, Arruti E, Tabernero I, Alvarez P (2018) Wire and arc additive manufacturing: a comparison between CMTand TopTIG processes applied to stainless steel. Welding in the World 62:1083-1096

6. Posch G, Chladil K, Chladil H (2017) Material properties of CMT - metal additive manufacturedduplex stainless steel bladelike geometries. Weld World 61:873-882

7. Hosseini VA, Högström M, Hurtig K, Bermejo MAV, Stridh L-E, Karlsson L (2019) Wire-arc additive manufacturing of a duplex stainless steel: thermalcycle analysis and microstructure characterization. Welding in the World

8. Leicher M, Treutler K, Kamper S, Wesling V (2019) Multimaterial design in der additiven Fertigung - Validierung der Machbarkeit. Tagungsband 3. Niedersächsisches Symposium Materialtechnik, pp $37-48$

9. Hornbogen E (1983) Werkstoffe. Springer-Verlag Verlin Heidelberg

10. Schulze G (2010) Die Metallurgie des Schweißens. Springer-Verlag Berlin Heidelberg, Heidelberg

11. Weißbach W (2010) Werkstoffkunde, 17. Auflage ed., Vieweg+ Teubner, Ed. Wiesbaden: GWV Fachverlage GmbH

12. Li X (2018) Additive manufacturing of advanced multi-component alloys: bulk metallic glasses and high entropy alloys. Adv Eng Mater 20

13. Zhang D, Sun S, Qiu D, Gibson MA, Dargusch MS, Brandt M, Qian M, Easton M (2018) Metal alloys for fusion-based additive manufacturing. Adv Eng Mater 20

14. METALCOR, “www.metalcor.de," 16. Januar 2019. [Online]. Available: www.metalcor.de/datenblatt/79/

15. DIN Deutsches Institut für Normung e.V., "Schweißzusätze Drahtelektroden, Drähte, Stäbe und Schweißgut zumSchutzgasschweißen von hochfesten Stählen -Einteilung (ISO 16834:2012);Deutsche Fassung EN ISO 16834:2012," Beuth Verlag GmbH, Berlin, 2012

16. Hermann Fliess \& Co. GmbH, "Fliess," 16. Januar 2019. [Online]. Available: www.fliess.com

17. Matthes K-J, Schneider W (2012) Schweißtechnik. Schweißen von metallischen Konstruktionswerkstoffen. München, Fachbuchverlag Leipzig im Carl Hanser Verlag

Publisher's note Springer Nature remains neutral with regard to jurisdictional claims in published maps and institutional affiliations. 